\title{
Capacidades estatais para 0 desenvolvimento rural no Brasil: análise das políticas públicas para a agricultura familiar
}

\author{
Cátia Grisa \\ Professora da Universidade Federal do Rio Grande do Sul. \\ Porto Alegre, Brasil \\ catiagrisa@yahoo.com.br \\ Karina Yoshie Martins Kato \\ Professora da Universidade Federal Rural do Rio de Janeiro \\ Rio de Janeiro, Brasil \\ anirakato@yahoo.com \\ Georges Gérard Flexor \\ Professor da Universidade Federal Rural do Rio de Janeiro \\ Seropédica, Brasil \\ gflexor@gmail.com
}

Silvia Aparecida Zimmermann

Professora da Universidade Federal da Integração Latino-Americana,

do Curso de Desenvolvimento Rural e Segurança Alimentar e do

Programa de Pós-Graduação em Políticas Públicas e Desenvolvimento.

silviazcpda@yahoo.com.br

Resumo $O$ trabalho analisa as capacidades estatais construídas para o desenvolvimento rural e agricultura familiar no Brasil. Para tanto, resgata-se como ocorreu o processo de construção de três políticas públicas (Pronaf, PAA e PNBP) e procura-se analisar a capacidade do Estado em promovê-las, implementá-las e apoiá-las ao longo dos anos. Compreende-se que as capacidades estatais criadas para o desenvolvimento rural emergiram a partir dos processos de redemocratização e descentralização política dos anos 1980, os quais permitiram a conformação de arranjos institucionais que ampliaram a interação entre o governo, a burocracia estatal e a sociedade civil organizada. Essa interação, associada ao estabelecimento de um governo de centro-esquerda a partir dos anos 2000, permitiu a criação de um ambiente político-institucional propício à conformação de um corpo político e de uma burocracia que colocaram a agricultura familiar e o desenvolvimento rural na agenda política do país e estabeleceram capacidades 
estatais para promovê-los. Contudo, tais capacidades, orientadas para segmentos da população historicamente marginalizados, são condicionadas pelo ambiente político-institucional e pelas relações de poder desiguais historicamente estabelecidas no meio rural brasileiro.

Palavras-chave: capacidades estatais, políticas públicas, desenvolvimento rural.

\section{Introdução}

A agricultura familiar brasileira foi historicamente marginalizada das ações do Estado. Até as décadas 1980/1990, não raro, essa categoria social era compreendida como um setor de subsistência, arcaico e marginal, destinado a desaparecer. Em momentos em que se discutia a industrialização nacional (anos 1950/60/70), por exemplo, alguns autores e vertentes políticas interpretavam ser mais eficiente para o Estado promover a modernização tecnológica daqueles estabelecimentos agrícolas considerados produtivos e estimular a realocação do excesso de mão de obra rural (parte da agricultura familiar) para atividades mais dinâmicas, como a industrialização nas áreas urbanas, do que promover a estruturação e dinamização econômica da "pequena produção" (Delgado, 2010; Delgado, 2005, 1985; Castro, 1977). As políticas agrícolas voltavam-se para os segmentos do mundo rural com aptidões para produzir, em grande escala, as matérias primas para a indústria de alimentos e os produtos de exportações - café, açúcar, trigo, milho, soja e carnes (Gonçalves Neto, 1997).

A análise desse período permite visualizar, deste modo, a capacidade do Estado em produzir ações (e omissões) que promoviam a industrialização, a urbanização, a modernização de setores agrários e, ao mesmo tempo, acentuavam a marginalização da agricultura familiar. Similar ao observado por Centeno $(2009$, p. 25$)$ ao analisar o papel do Estado na América Latina, esta trajetória deixar transparecer que

a capacidade do Estado é maior nas cidades que nas zonas rurais, na capital do que nas províncias, e nos bairros ricos do que nos pobres. É muito provável que a debilidade mais importante do Estado latino-americano em geral seja a sua incapacidade em proporcionar serviços para aqueles segmentos da população que necessitam deles.

A partir dos anos 1990, contudo, consolida-se uma importante mudança institucional no Brasil. O Estado passou progressivamente a reconhecer política e institucionalmente a agricultura familiar, possibilitando a construção de um amplo conjunto de políticas públicas e quadros normativos específicos para a categoria social. Neste processo, criou-se um Ministério específico (Ministério do Desenvolvimento Agrário - MDA), com diversas secretarias (dentre elas a Secretaria da Agricultura Familiar); construiu-se uma burocracia profissionalizada e qualificada para tratar da categoria social (ainda que com limitações em termos de quantidade de recursos humanos); estabeleceram-se espaços de participação social (por exemplo, o Conselho Nacional de Desenvolvimento Rural Sustentável - CONDRAF e os diálogos para a construção dos Planos Safra da 
Agricultura Familiar); ampliaram-se os recursos públicos aplicados; construíram-se leis que reconheceram a identidade social e cultural de grupos e segmentos sociais que tradicionalmente estavam marginalizados; e implementaram-se programas que atuaram na esfera da produção, da comercialização, e das condições de vida das unidades familiares.

Esta capacidade estatal brasileira construída para o fortalecimento da agricultura familiar e do desenvolvimento rural foi reconhecida internacionalmente. Diversos documentos políticos, institucionais e acadêmicos ressaltam a proeminência das políticas brasileiras para a agricultura familiar e a importância de difundir essas experiências para outros contextos (Sabourin; Samper; Massardier, 2015; FAO, 2015, 2014;WFP, 2013). Ao mesmo tempo, diversos países vieram conhecer a experiência brasileira in loco, bem como convidaram o quadro burocrático para colaborar na "transferência" dessas ações às suas realidades por meio de acordos de cooperação bilaterais ou trilaterais. O Brasil passou a ser projetado internacionalmente como o grande laboratório de políticas públicas inovadoras para o combate à pobreza e promoção do desenvolvimento rural.

Considerando a magnitude e a importância da mudança ocorrida na capacidade do Estado em intervir na agricultura familiar e no desenvolvimento rural, este trabalho tem como objetivo analisar a construção institucional das políticas públicas, destacando a capacidade do Estado em promovê-las, implementá-las e apoiá-las ao longo dos anos. Algumas questões chamam particularmente a atenção na análise: Quais foram as condições que permitiram a formulação de políticas de agricultura familiar no Brasil, num contexto marcado pelo tratamento preferencial à agricultura em grande escala (setor patronal)? Que instrumentos e instituições públicas foram criados para garantir o apoio a essa categoria social? Qual o apoio financeiro dado? Qual é a legitimidade das ações do Estado em relação às demandas da agricultura familiar? Qual é a sustentabilidade (continuidade) dessas capacidades estatais diante da dualidade agrária brasileira e das oscilações políticas?

Parte-se da hipótese de que as capacidades estatais criadas para o desenvolvimento rural emergiram a partir dos processos de redemocratização e de descentralização política dos anos 1980 (reforçados na Constituição Federal de 1988), os quais permitiram a conformação de arranjos institucionais que ampliaram a interação entre o governo, a burocracia estatal e a sociedade civil organizada. Essa interação, associada ao estabelecimento de um governo de centro-esquerda a partir dos anos 2000, permitiu a criação de um ambiente político-institucional propício à conformação de um corpo político e de uma burocracia que colocaram a agricultura familiar e o desenvolvimento rural na agenda política do país e estabeleceram capacidades estatais para promovê-los. Essas capacidades estatais de construção e implementação das políticas públicas orientadas para uma população historicamente marginalizada, contudo, são condicionadas pelo ambiente político-institucional e pelas relações de poder desiguais historicamente estabelecidas no meio rural brasileiro.

Para responder às perguntas e confrontar a hipótese, o artigo discute a trajetória de três políticas públicas: o Programa Nacional de Fortalecimento da Agricultura Familiar (Pronaf), o Programa de Aquisição de Alimentos (PAA) e o Programa Nacional de Produção e Uso de Biodiesel (PNPB). Criado nos anos de 1990, o Pronaf foi a primeira polí- 
tica pública voltada exclusivamente para a agricultura familiar e, atualmente, é a principal política agrícola direcionada para a categoria social. O PAA inovou ao articular iniciativas de política agrícola com ações de segurança alimentar e nutricional (SAN) (Delgado; Conceição; Oliveira, 2005), abrindo uma "janela de oportunidades” (Kingdon, 1984, p. 165) para a emergência e fortalecimento dos mercados institucionais para a agricultura familiar. Por sua vez, o PNPB busca promover a inclusão produtiva dos pequenos agricultores familiares nas estratégias de produção de bicombustíveis e, com isto, promover o desenvolvimento regional de áreas rurais do Semiárido brasileiro. O Programa tentava articular a produção de energia - historicamente realizada pela produção em larga escala - à produção proveniente da agricultura familiar.

A apresentação da análise foi organizada em mais cinco seções. A primeira recupera o debate sobre capacidades estatais e detalha o quadro metodológico adotado no artigo. Baseado neste, as três seções seguintes analisam a construção e a implementação das políticas públicas selecionadas. ${ }^{1}$ Por fim, são realizadas algumas considerações sobre os desafios das capacidades estatais para a agricultura familiar diante da dualidade agrária brasileira e de algumas mudanças políticas recentes.

\section{A Perspectiva Analítica das Capacidades Estatais}

O impulso inicial da literatura sobre capacidades estatais surgiu nos anos 1980, com os trabalhos desenvolvidos por autores neo-weberianos, como Evans, Rueschemeyer e Skocpol (1985) e Skocpol e Finegold (1982). Para Evans, Rueschemeyer e Skocpol (1985, p. 3), "um interesse repentino no Estado foi observado nas Ciências Sociais Comparativas na última década". Este "retorno do Estado" resultava do reconhecimento de que as instituições e a burocracia tinham a capacidade de moldar a trajetória de desenvolvimento econômico e social de um país. De um modo geral, esses trabalhos procuravam enfatizar a autonomia do Estado e seu papel na condução dos processos de industrialização tardia. Essas capacidades permitiam ao Estado reafirmar objetivos próprios e não ser apenas um mero instrumento da burguesia (como enfatizado por marxistas) ou de grupos de interesses específicos (conforme atribuído por autores pluralistas) (Gomide, 2016).

A partir desses trabalhos pioneiros se desenvolveu uma extensa literatura sobre a autonomia, a burocracia e a capacidade da ação estatal, denominada genericamente pelo conceito de "capacidade estatal". Por conta do contexto em que foi realizada, boa parte dessa literatura inicial se debruçava sobre a compreensão do papel do Estado na transformação econômica, não raro, na industrialização. Como menciona Cingolani (2013),

1 A análise da trajetória das três políticas públicas parte dos acúmulos de investigação já realizados pelos autores. As políticas selecionadas já foram objeto de investigação de teses de doutorado e de projetos de pesquisa (Grisa et al., 2016; FLexor; Kato, 2015; Grisa et al., 2015; Kato, 2012; Grisa, 2012; Zimmerman, 2011; Flexor et al., 2011), os quais envolveram entrevistas-semiestruturadas com os principais atores envolvidos em cada programa, pesquisa documental e levantamento de dados secundários. 
grande parte desta literatura pioneira tendeu a destacar as dinâmicas e características internas do Estado e de suas burocracias, sua qualificação técnico-administrativa e sua autonomia na tomada de decisões. Para Pereira (2014, p. 32), “a capacidade estatal era analisada como o produto do insulamento das burocracias estatais dos grupos sociais, algo que fortaleceria a autonomia estatal de escolher políticas a partir de uma lógica racional e de implementá-las de forma coerente".

No início dos anos 1990, a ênfase no insulamento do Estado deu lugar para um maior reconhecimento da importância das relações estabelecidas entre Estado e sociedade como potencializadoras das capacidades estatais. Essas relações possibilitariam a construção de políticas com maior sustentação política ao serem frutos de um amplo e conflituoso processo de negociação e de legitimação e, portanto, mais próximas às especificidades dos seus beneficiados. Os estudos de Migdal (1988), Mann (2008) e, principalmente, Evans (1995; 1993), com a noção de autonomia inserida, foram particularmente importantes nesse sentido. Partindo da análise de diferentes estruturas de Estado, Evans (1993, on-line) argumenta que a capacidade de atuação e de transformação do Estado

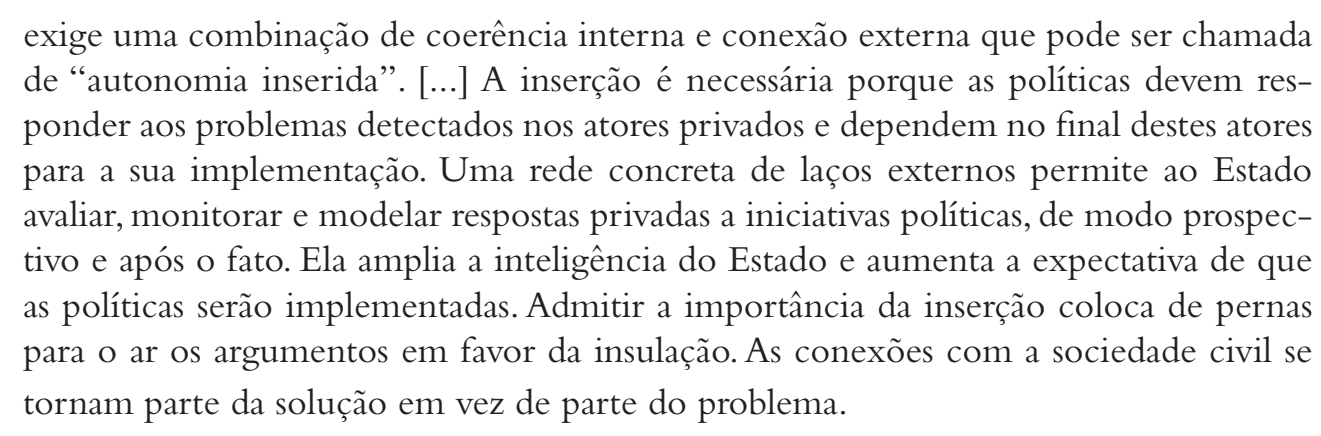

A mudança nos estudos sobre capacidades estatais ampliou seu aporte analítico para entender a trajetória recente de construção das políticas de desenvolvimento rural (após o processo de redemocratização do Brasil iniciado no final dos anos 1980), quando os movimentos sociais da agricultura familiar passaram a exigir participação e diálogo na construção e na implementação das políticas públicas e foram estabelecidos inúmeros espaços de participação social com a Constituição Federal de 1988. Com efeito, no caso brasileiro, a democratização resultou no fortalecimento da participação social, inaugurando um período de maior cooperação entre Estado e sociedade civil na construção de políticas públicas. Entretanto, uma vez colocado em marcha, esse processo fortaleceu e exigiu o aprofundamento das capacidades estatais com vistas a possibilitar "a inclusão de múltiplos atores, o processamentos dos conflitos decorrentes e a formação de coalizões políticas de suporte para os objetivos e as estratégias a serem adotadas" (Gomide; Pires, 2014, p. 21) 2.

2 Como argumentam Gomide e Pires (2014, p. 21), a redemocratização demanda "novas capacidades do Estado, além das necessidades de uma burocracia profissional, coesa e meritocrática. Ou seja, no contexto de um ambiente institucional caracterizado pela existência de instituições representativas, participativas e de controle (social, burocrático e judicial), são necessárias também capacidades políticas para a inclusão de múltiplos atores, o processamento dos conflitos decorrentes e a formação de coalizões políticas de suporte para os objetivos e as estratégias a serem adotadas." 
Nesse sentido, as capacidades estatais e as políticas públicas se fortaleceram mutuamente: o processo de democratização abriu possibilidades para maior diálogo Estado-sociedade civil, que resultou na criação de inúmeras políticas públicas inovadoras que, por sua vez, na medida em que foram sendo implementadas, passaram crescentemente a exigir o aprofundamento da democracia e o fortalecimento das capacidades estatais nessa direção.

Desde a sua emergência, o conceito de capacidade estatal tem sido uma âncora analítica usada para analisar diversas relações entre o Estado, a sociedade e o desenvolvimento, por exemplo: a) ao analisar o desenvolvimento industrial, Evans e Rauch (1999) evidenciaram que há uma correlação positiva entre o crescimento econômico e a existência de estrutura burocrática weberiana; b) um dos argumentos básicos do influente Why Nations Fail, de Acemoglu e Robinson (2013), é que, sem um Estado centralizado e capaz de garantir direitos de propriedades seguros - condição para a inovação - não haveria desenvolvimento econômico de longo prazo; c) Fearon e Laitin (2003) analisam a relação entre conflitos, guerras e capacidades estatais, afirmando que as razões para as inúmeras guerras civis vivenciadas no processo de descolonização decorriam mais da falta de capacidades estatais e menos das divisões étnicas; d) Wang e Xu (2015) evidenciam uma relação positiva entre os regimes democráticos e a capacidade administrativa, a capacidade de levantar tributos e o poder de coerção do aparato estatal, considerando que os conflitos sociais (presentes nos regimes democráticos) estimulam, de forma contínua, a formação de capacidades estatais (estas, por sua vez, estariam diretamente relacionadas com os resultados das urnas e com a governabilidade); e) Gomide e Pires (2014) discutem as possibilidades e os desafios da execução de políticas desenvolvimentistas em um contexto democrático, que exige burocracias governamentais com altas capacidades de coordenação e execução acompanhadas de espaços de participação, diálogo e negociação entre interesses diversos; e, f) nesta mesma direção, Pereira (2014) evidencia como as capacidades de diferentes agências estatais de estabelecer diálogo com os atores da sociedade e de colaboração e concertação entre burocracias possibilitam (ou não) a incorporação de demandas de atores politicamente marginais no processo político.

Trata-se, portanto, de um conceito "guarda-chuva" para a compreensão da relação entre Estado, sociedade e trajetória de desenvolvimento econômico e social. No entanto, ao mesmo tempo em que é muito rica, essa diversidade de abordagens pode dificultar a operacionalização do conceito de capacidades estatais (Cingolani, 2013). Skocpol (1985), por exemplo, define capacidade estatal como aquela necessária para implementar metas oficiais na presença de oposição de grupos sociais poderosos. Migdal (1988) a associa à habilidade da burocracia para alcançar mudanças sociais através do planejamento, de políticas públicas e de ações estatais. Já o Banco Mundial (1977) define como a habilidade de promover a ação coletiva eficientemente. Na perspectiva de Evans (2004, p. 37), as capacidades estatais possibilitam que os Estados fomentem transformações sociais e o desenvolvimento, sendo influenciadas pelas características estruturais do Estado (sua organização interna e as relações que estabelecem com a sociedade). 
São variadas também as formas de identificação dessas distintas capacidades estatais. Hanson e Sigman (2011) entendem que caberia ao Estado seis funções principais: manter a ordem social, garantir os direitos de propriedades, prover alguns bens públicos, garantir a execução dos contratos, ter competências técnicas e coordenar as informações e medidas. Em trabalho semelhante, Hendrix (2010), defende que os elementos mais importantes seriam a qualidade da burocracia e o nível de arrecadação.

Ao aplicar o conceito ao Brasil, Gomide e Pires (2014, p. 20) relacionam as capacidades estatais com os componentes técnico-administrativos e políticos do Estado. O primeiro se refere à competência para levar a efeito suas políticas, produzindo ações coordenadas e orientadas para a produção de resultados. O último é a habilidade em expandir os canais de interlocução, negociação com os diversos atores sociais, processando conflitos e prevenindo a captura por interesses específicos. Analogamente, Bichir (2015) compreende capacidades estatais como a habilidade dos Estados para formular e implementar políticas, bem como para construir base de apoio entre os atores sociais, políticos e econômicos relevantes.

Ao aplicar o conceito para a América Latina, Centeno (2009) alerta para a necessidade de considerarmos fatores históricos e idiossincrasias na formação dessas capacidades. O Chile e o Brasil, por exemplo, têm conseguido estabelecer competências administrativas em diversas áreas e desenvolver capacidades para arrecadar tributos que os demais países da região ainda não alcançaram. Para a autora, a orientação política dos governos é uma variável chave para entender a relação entre democracia e desenvolvimento de capacidades estatais. Grassi e Memoli (2016) concordam e ressaltam, contudo, que essa relação seria positiva na presença de governos mais progressistas, e desapareceria em governos de partidos conservadores.

Examinando as capacidades estatais em países emergentes, Gomide (2016) reconhece seis dimensões principais: coercitiva, fiscal, administrativa, relacional, legal e política. A coercitiva está associada à função de manter a ordem pública e defender o território nacional. A fiscal enfatiza as dificuldades do Estado em extrair recursos da sociedade para financiar o seu funcionamento e as políticas públicas. A administrativa refere-se ao potencial de implementação das políticas públicas, o que requer um corpo burocrático profissional, dotado de recursos e de instrumentos para tal. A relacional é referente à habilidade da burocracia em se conectar com os diferentes grupos sociais, e à capacidade de mobilizar recursos políticos para tornar sua ação mais efetiva. A legal consiste na habilidade para definir e garantir as leis e regulamentos. E, por fim, a política refere-se ao poder de estabelecer a agenda política, fazendo valer suas prioridades.

Visando analisar as capacidades estatais formadas pelo Estado brasileiro que possibilitaram a elaboração e implementação de políticas públicas inovadoras para a agricultura familiar e o desenvolvimento rural, o artigo define capacidade estatal como o conjunto de recursos institucionais e financeiros que políticos, burocratas e as coalizões que os apoiam conseguem efetivamente mobilizar para formular e implementar as políticas públicas que vão de encontro aos interesses de grupos sociais detentores de poder num determinado setor. 
De modo operacional, três capacidades estatais serão consideradas na análise do Pronaf, PAA e PNPB, sendo elas: i) capacidades democráticas; ii) capacidades institucionais; e, iii) capacidade financeira. A literatura revisada e a experiência brasileira recente sinalizam que essas três capacidades estatais seriam fundamentais para a construção e a implementação de políticas públicas voltadas para a agricultura familiar e para o desenvolvimento rural. Capacidades democráticas são as estruturas formais e informais voltadas para a ampliação do diálogo e da interação entre Estado, mercado e organizações sociais da agricultura familiar em torno da elaboração e da implementação de políticas públicas de desenvolvimento rural. Essas capacidades resultam em maior legitimação das políticas públicas, conferindo-lhes maiores possibilidades de adaptação e flexibilidade às demandas do público beneficiário e/ou aos contextos locais. Por capacidades institucionais compreende-se a estrutura institucional (ministérios, secretarias, conselhos, leis, decretos etc.) criada para coordenar, sustentar, implementar, monitorar e avaliar os processos que estão envolvidos em todo o ciclo da política pública. Trata-se dos instrumentos que garantem marcos legais para estruturar as políticas públicas e que, por conseguinte, oferecem maior sustentabilidade diante de oscilações e pressões políticas. E, por fim, financeira é a capacidade do Estado de sustentar financeiramente as políticas públicas estabelecidas, em especial, a capacidade de direcionar recursos públicos para ações definidas como prioritárias na agenda política, não obstante a oposição e contestação de segmentos sociais poderosos.

\section{Capacidades Estatais para a Construção e Execução do PRONAF}

As mudanças políticas e institucionais iniciadas com o processo de redemocratização no Brasil, em meados dos anos 1980, abriram oportunidades para os movimentos sociais e sindicais vinculados aos trabalhadores rurais se reorganizarem e pautarem a construção de políticas públicas ao Estado. As possibilidades abertas com os debates da Constituinte, as negociações para as Leis Agrícola (1991) e Agrária (1993) e a emergência dos Conselhos de participação social alteraram a forma de interação entre os agricultores familiares e o Estado. Algumas demandas dos representantes da agricultura familiar foram incorporadas e institucionalizadas no momento de construção da Lei Agrícola, a qual reconheceu a diversidade dos agricultores brasileiros e previu a construção de uma política agrícola diferenciada para os pequenos produtores (Delgado, 1994). Todavia, essas concessões ficaram aquém das reivindicações, prevalecendo as ideias, os interesses e o poder da agricultura patronal na construção das políticas públicas.

No início dos anos 1990, em virtude de medidas econômicas neoliberais adotadas, as organizações da agricultura familiar recrudesceram as pressões e contestações por políticas agrícolas diferenciadas. Os Gritos da Terra iniciados em 1994 foram particularmente importantes. Em respostas a eles, o Governo Federal criou o Pronaf em 1995. Deste modo, a atuação dos movimentos sociais e sindicais foi fundamental para a emergência da 
primeira política nacional direcionada especificadamente para os agricultores familiares (SAntos, 2011; Schneider; Cazella; Mattei, 2004).

Todavia, como reconhece a literatura, a mudança paradigmática observada nos estudos rurais (que passaram a destacar a pemanência e a importância da agricultura familiar nos países desenvolvidos) e a atuação e os interesses da burocracia e dos designados politicamente também contribuíram para a emergência do Pronaf (Grisa, 2012; Santos, 2011; Schneider; Cazella; Mattei, 2004). Gestores públicos vinculados à Secretaria do Desenvolvimento Rural do Ministério da Agricultura, Pecuária e Abastecimento (MAPA) reconheciam a importância da agricultura familiar para o desenvolvimento do país e a necessidade de construir uma política que a fortalecesse. Ademais, havia interesses do governo federal em manter a ordem social no campo e certa influência no sindicalismo dos trabalhadores rurais (Grisa, 2012; Medeiros, 2001).

$\mathrm{Na}$ confluência entre mobilizações sociais e autonomia relativa, o Pronaf foi negociado e institucionalizado, inicialmente pela Resolução no.2.191 de 24 de agosto de 1995 do Conselho Monetário Nacional, e, logo em seguida, por meio do Decreto nº 1.946 , de 28 de junho de 1996, da Presidência da República. Além de financiamento da produção agrícola (crédito de custeio e de investimento), o PRONAF contemplou mais três linhas: i) PRONAF Infraestrutura;ii) capacitação e profissionalização dos agricultores familiares, conselheiros municipais e equipes técnicas responsáveis pela implementação dos Planos Municipais de Desenvolvimento Rural; iii) negociação com os órgãos setoriais para promover o ajustamento de políticas públicas à realidade dos agricultores familiares.

Para dar conta dessa magnitude, foi necessário construir um amplo arranjo institucional que envolvia, em distintos níveis, diferentes atores e arenas de participação, a exemplo do Conselho Nacional do Pronaf (atualmente CONDRAF), dos Conselhos Estaduais de Desenvolvimento Rural, e dos Conselhos Municipais de Desenvolvimento Rural, os quais foram criados especialmente para dar operacionalidade ao Programa. Assim, se a democratização abriu espaço para diálogos entre Estado e sociedade civil na construção de políticas públicas, a criação do Pronaf e dessas institucionalidades inauguraram um novo ciclo de fortalecimento das capacidades democráticas na promoção do desenvolvimento rural.

Ademais, a Portaria nº 386/1997 estabeleceu a Declaração de Aptidão ao PRONAF (DAP) como um "certificado" de adequação dos beneficiários aos critérios de enquadramento na categoria social "agricultor familiar", a qual seria fornecida pelos sindicatos filiados à Confederação dos Trabalhadores na Agricultura (CONTAG) e à Confederação Nacional da Agricultura (CNA), e pelas empresas estaduais de extensão rural. A DAP, utilizada hoje por mais de 16 políticas públicas, foi uma importante inovação que possibilitou a diversificação das políticas públicas para a agricultura familiar.

Esses normativos e institucionalidades foram reforçando as capacidades estatais na execução do Programa e no tratamento da agricultura familiar. Com efeito, na medida em que o Pronaf foi sendo estruturado, operacionalizado e demandado cada vez mais, tanto ele como a categoria da agricultura familiar, ganharam maior reconhecimento e legitimidade 
política e institucional (Santos, 2011). Elucida essa trajetória a institucionalização, em 1999, do Ministério do Desenvolvimento Agrário (MDA) e da Secretaria Nacional da Agricultura Familiar - que passaram a ser os responsáveis pela execução do Pronaf; a criação do Seguro da Agricultura Familiar-SEAF e do Programa de Garantia de Preço da Agricultura Familiar (PGPAF), diretamente vinculados ao Pronaf; a emergência de um amplo conjunto de políticas públicas a partir de 2003; e a definição da Lei da Agricultura Familiar (Lei nº. 11.326) em 2006, que delimita conceitualmente a agricultura familiar (em grande medida inspirada na definição dada pelo Pronaf) e delineia diretrizes para a formulação da Política Nacional da Agricultura e Empreendimentos Familiares Rurais. Assim, pode-se dizer que o Pronaf abriu uma "janela de oportunidades", tal qual utilizado por Kingdon (1984), ou pode ser considerado um "momento crítico", nos termos de Mahoney (2001), para que um novo leque de políticas públicas fosse institucionalizado e as capacidades estatais no tratamento do Programa, da agricultura familiar e do desenvolvimento rural reforçadas.

Tão logo o Pronaf começou a ser executado, diversas mudanças institucionais foram realizadas, seja em virtude da continuidade das mobilizações, pressões e participação/diálogos das organizações da agricultura familiar, seja em decorrência dos aprendizados e das proposições da burocracia conformada para executar o Programa. Tais alterações visavam à ampliação da sua capilaridade e torná-lo mais próximo às especificidades da agricultura familiar. Redefinições nos critérios do público beneficiário, criação dos "Grupos" do Pronaf (A, B, C, D e E), estabelecimento de linhas (Pronaf Mulher, Jovem, Agroecologia, Agroindústria etc.), e readequação das condições creditícias (taxas de juros, prazos de pagamento etc.) são alguns exemplos neste sentido.

Ilustrando a abertura ao diálogo e a permeabilidade do Programa às demandas da sociedade civil, cita-se, por exemplo, a criação do "Pronafinho" em 1997, uma linha de crédito direcionada aos agricultores descapitalizados (distinto do público inicialmente estabelecido). As organizações da sociedade civil começaram a pautar a necessidade do Pronaf de atender a diversidade socioeconômica da agricultura familiar considerando que as regras e normas inicialmente estabelecidas poderiam reproduzir desigualdades expressivas. Deste modo, nas palavras de Abramovay e Piketty (2005, p. 62), "Criou-se uma nova linha de crédito no interior do Pronaf voltada a agricultores bem próximos da linha de pobreza, ou seja, em média, um terço do nível de renda bruta dos primeiros beneficiários do Programa."

Por sua vez, elucidando a autonomia relativa da burocracia estatal, citamos a criação da Linha Mais Alimentos, em 2008, que tinha o objetivo de financiar a aquisição de máquinas e equipamentos agrícolas. Criada em meio à crise internacional dos alimentos iniciada em 2007, a linha tinha como objetivos financiar a modernização das propriedades familiares, fortalecer e aumentar a produção de alimentos da agricultura familiar e, ao mesmo tempo, dar impulso à indústria nacional de máquinas e equipamentos afetada pela crise financeira internacional. Essa linha emergiu do protagonismo da burocracia estatal como uma resposta ao cenário de crise internacional, sendo logo apropriada e reiterada por representantes da agricultura familiar, os quais passaram a ressaltar sua importância e cobrar a sua permanência e ampliação. 
Atualmente o Pronaf é a política agrícola mais importante para a agricultura familiar, seja em virtude de sua capilaridade, chegando a mais de 97\% dos municípios brasileiros (Brasil, 2015), seja em decorrência de sua magnitude financeira ${ }^{3}$. Desde a sua criação, é perceptível o crescimento considerável dos recursos aplicados, os quais passaram de $\mathrm{R} \$ 650$ milhões em 1996 para $\mathrm{R} \$ 21,7$ bilhões de reais em 2015. Para o Plano Safra da Agricultura Familiar 2016/2017 foram anunciados R $\$ 30$ bilhões de reais (Brasil, 2016).

Embora existam críticas - oriundas dos estudiosos do meio rural, dos movimentos sociais da agricultura familiar, e das organizações do agronegócio - ao modelo de agricultura apoiado pelo Programa; ao caráter seletivo diante da diversidade produtiva e socioeconômica da agricultura familiar; à sua forma de organização; e aos subsídios conferidos (Bianchini, 2015; Aquino; Schneider, 2010; Guanziroli, 2007; Mattei, 2006), o Pronaf é a política agrícola mais expressiva financeira, institucional e politicamente para a agricultura familiar. Ela marcou o reconhecimento político e institucional do Estado à categoria social e, igualmente, o reconhecimento do caráter dual da agricultura nacional. Ainda que suscetível às mudanças políticas e econômicas - a exemplo de alterações creditícias em termos de elevação das taxas de juros na safra 2015/2016 -, o Pronaf parece ser a política agrícola para a agricultura familiar com capacidades institucionais e financeiras mais estruturadas. As mudanças que devem ser anunciadas para a nova safra agrícola (2017/2018) - em contexto politicamente distinto daquele dos últimos anos, a exemplo da extinção do MDA e da presença de uma nova coalizão política à frente das políticas públicas para a agricultura familiar - poderão atestar (ou não) a sustentabilidade das capacidades democráticas, institucionais e financeiras construídas pelo Estado.

\section{Capacidades Estatais para a Construção e Execução do PAA}

As mudanças políticas oportunizadas com as eleições presidenciais em 2002 abriram a possibilidade de que atores da sociedade civil que discutiam SAN, desde a década de $1990^{4}$, adentrassem na estrutura do Estado e procurassem construir capacidades estatais nos temas da fome e da SAN. Muitos desses atores participaram também da construção do "Projeto Fome Zero: uma proposta de Política de Segurança Alimentar para o Brasil", em 2001, já no bojo da campanha eleitoral no ano seguinte.A sua elaboração representou, como aludiu Menezes (2010, p. 247), "[...] a culminância de todo um processo anterior

3 Similar à agricultura empresarial, o Pronaf tem como fonte de seus recursos o Fundo de Amparo ao Trabalhador (FAT), a exigibilidade bancária, a poupança rural (MCR 6-4), os Fundos Constitucionais, as Operações Oficiais de Crédito (OOC), os recursos próprios equalizáveis (RPE) e o depósito interfinanceiro vinculado ao crédito rural.

4 Trata-se dos atores vinculados ao "Governo Paralelo", que propôs a Política Nacional de Segurança Alimentar (não implementada) em 1991; à mobilização "Ação da Cidadania Contra a Fome, a Miséria e pela Vida", liderada pelo sociólogo Herbert de Souza (o Betinho), e à respectiva "Campanha Nacional de Combate à Fome" em 1993; e ao Conselho Nacional de Segurança Alimentar e Nutricional (CONSEA) estabelecido em 1994. 
de formulações e práticas na luta contra a fome e pela segurança alimentar e nutricional no Brasil experimentadas por governos (nos níveis municipal e estadual) e organizações sociais." Com efeito, o combate à fome e o "Programa Fome Zero" tornaram-se prioridades no primeiro mandato do Governo Lula, sendo logo institucionalizadas medidas importantes nesse sentido, a exemplo da criação do Ministério Extraordinário de Segurança Alimentar e Combate à Fome (MESA), do Programa Cartão Alimentação, e da recriação do Conselho Nacional de Segurança Alimentar e Nutricional. Compreendia-se, este último, como um espaço importante para ampliar as capacidades democráticas do Estado, ao construir políticas de SAN em diálogo com a sociedade civil.

Tão logo o CONSEA foi restabelecido em 2003, o mesmo começou a discutir diretrizes para as ações na área de alimentação e nutrição, incluindo proposições na interface entre agricultura familiar e SAN. Um dos primeiros trabalhos do CONSEA foi o documento "Diretrizes de Segurança Alimentar e do Desenvolvimento Agrário para o Plano Safra - 2003/2004 (Subsídios Técnicos do CONSEA)", sendo que deste documento emergiu as ideias para a criação do PAA.

O PAA foi criado em 2003, visando à articulação da compra de produtos da agricultura familiar com ações de SAN (distribuição de alimentos) para a população em vulnerabilidade social. Cabe destacar que, em termos de institucionalidades, a criação do Programa esteve circunscrita ao Artigo 19 da Lei nº.10.696, a qual tratava da repactuação e alongamento das dívidas oriundas de operações do crédito rural. Como o normativo de criação do PAA teve que ser sintético para "aproveitar a carona" de outra Medida Provisória, parte da regulamentação do Programa foi realizada por meio do Decreto $n^{\circ} .4 .772 / 2003$. Essa frágil institucionalização foi muito questionada pelo CONSEA e organizações da sociedade civil, sendo que, em 2011, o PAA foi estruturado pela Lei nº 12.512 de 14 de outubro de 2011, e regulamentado pelo Decreto nº 8.293 de 12 de agosto de 2014.

Embora concebido como uma ação estruturante no Programa Fome Zero, o PAA apresentou certa "timidez" em seus anos iniciais, seja em virtude de sua fase de experimentação ou de projetos piloto, seja em decorrência de certas mudanças políticas (extinção do MESA e alterações em suas concepções originais), ou ainda por não ter sido prioridade na pauta de reivindicação das organizações da agricultura familiar (o que veio a ocorrer em anos seguintes) (Porto, 2014; Muller, 2007; Delgado; Conceição; Oliveira, 2005). Com a expansão do Programa e a evidência de seus resultados para o fortalecimento da agricultura familiar e da SAN, o Programa ganhou importante impulso nacional e internacional, servindo de exemplo a ser "exportado" para outros países ${ }^{5}$.

O arranjo institucional do PAA envolveu a criação de seis modalidades de funcionamento (Compra com Doação Simultânea, Formação de Estoques, Compra Direta, Compra Institucional, Incentivo à Produção e ao Consumo de Leite, e PAA Sementes), as quais envolvem recursos financeiros e capacidades administrativas do MDA, MAPA/ CONAB, MDS, governos estaduais, governos municipais, organizações da agricultura fa-

Cita-se, para ilustrar, o Purchase from Africans for Africa (PAA Africa), implementado em cinco países da África Subsariana, e as iniciativas incitadas no Haiti e em diversos países latino-americanos. 
miliar, organizações socioassistenciais e mediadores sociais da sociedade civil (geralmente organizações não governamentais e extensionistas rurais). Destaca-se que algumas modalidades envolvem participação intensa da sociedade civil na construção e na execução dos projetos de comercialização.

O Programa também conta com um grupo gestor formado pelo MDS, Ministério da Fazenda, Ministério do Planejamento, Orçamento e Gestão (MPOG), MAPA/CONAB, MDA e MEC. Adicionalmente, a partir de demanda do CONSEA, o Grupo Gestor dispõe de um comitê consultivo (estabelecido em 2012) composto por representantes governamentais e da sociedade civil, com a finalidade de manter canal de diálogo sobre a implementação e aperfeiçoamentos do PAA.

O PAA incorpora também mecanismos de controle social. Essa função é realizada nos espaços de articulação e coordenação da sociedade civil e órgãos governamentais, sobretudo, nos conselhos relacionados ao campo da agricultura familiar, do desenvolvimento rural, e da SAN. O CONDRAF e o CONSEA (em suas escalas nacional, estadual e municipal) são particularmente importantes neste sentido.Aliás, como comenta Menezes (2010, p. 253), "o CONSEA não foi apenas a instância onde foi gerado o Programa, mas permanente espaço de acompanhamento e formulação de proposta para seu aperfeiçoamento."

Nesta trajetória, os recursos financeiros aplicados pelo PAA saltaram de R $\$ 145$ milhões em 2003, quando beneficiou pouco mais de 40 mil agricultores familiares, para quase 840 milhões de reais em 2012, contemplando mais de 180 mil unidades familiares (nesse intervalo de tempo, o crescimento nem sempre foi linear). 2012 foi ano em que o Programa atingiu sua maior expressividade numérica, em termos de recursos aplicados, número de agricultores familiares beneficiados, alimentos adquiridos e organizações consumidoras contempladas. Não obstante o crescimento, é importante destacar que, considerando as dimensões da agricultura familiar brasileira e as potenciais contribuições para a SAN, trata-se de um programa pequeno em termos orçamentários (MIELITZ, 2014). Com efeito, este desempenho ficou aquém das reivindicações das organizações da agricultura familiar e do CONSEA (FETRAF-SUL, 2007; BRASIL, 2007). ${ }^{6}$

A partir de 2013, o PAA entrou em uma nova trajetória, fruto de uma atuação mais incisiva das capacidades estatais de controle (órgãos de controle da gestão pública federal, como a Controladoria Geral da União), por vezes descontextualizadas das especificidades da agricultura familiar. A execução do PAA tornou-se mais intensa em regras formais e documentos exigidos, assim como a fiscalização do Programa tornou-se mais enérgica e menos flexível. Como observaram Grisa et al. (2015, p. 156) em pesquisa realizada no Rio Grande do Sul e Rio Grande do Norte,

De um arranjo e ambiente institucional mais permeável às demandas da agricultura familiar, o que permitia maior flexibilidade institucional e diálogo com

6 A atuação do CONSEA foi importante em diversos momentos para garantir suplementações orçamentárias ao Programa.Em 2008 e 2010, o CONSEA emitiu inúmeros documentos solicitando ao Presidente da República a revisão das limitações de empenho ao PAA, para salvaguardar e ampliar os recursos destinados ao Programa. 
os espaços locais, forjou-se um novo ambiente institucional mais complexo em termos de regras formais e menos permeável às especificidades organizacionais, produtivas e estruturais da categoria social, repercutindo na performance do Programa e nas formas de governança.

Como resultado desse processo e de mudanças normativas realizadas no Programa sendo várias dessas em reação ao incremento do controle -, a execução orçamentária do PAA caiu pela metade, seja em termos de recursos financeiros aplicados, seja em termos de agricultores familiares beneficiados, ou ainda de organizações consumidoras contempladas. Conforme dados preliminares do PAADATA, em 2015 foram aplicados cerca de $\mathrm{R} \$ 555$ milhões de reais na aquisição de alimentos de 95.971 agricultores familiares. Para 2017, o orçamento preliminar do Programa é de R \$ 337,00 milhões (Brasil, 2016).

É importante destacar que o arrefecimento do PAA recaiu principalmente sobre a modalidade Compra com Doação Simultânea, operada pela Conab, a qual foi objeto de maior controle e investigação. Chama a atenção que esta foi a modalidade que teve maior projeção política nacional e internacional e que as capacidades de execução dependiam da interação com as organizações da sociedade civil. Nesse processo de arrefecimento da modalidade compra com doação simultânea, outros formatos e modalidades foram estimulados, notadamente a Compra com Doação Simultânea executada via Termo de Adesão com governos estaduais e municipais, e a Compra Institucional, a primeira incitada desde 2011 e a segunda desde a sua criação em 2012. Para Porto (2014, p. 111), os eventos ocorridos em 2013 e as mudanças desencadeadas contribuíram para fortalecer a participação dos entes federativos no Programa:

Associado a isso, como vimos, encontra-se o esforço em ampliar o ingresso dos municípios como "parceiros" na execução do PAA, com a justificativa de assegurar maior capacidade de controle nas operações do Programa, por meio da descentralização das ações governamentais e, ao mesmo tempo, transferindo parte da responsabilidade da gestão.

Desse modo, analisado em uma perspectiva histórica a partir da abordagem das capacidades estatais, pode-se afirmar que: i) o Programa nasceu do diálogo entre Estado e sociedade civil, foi monitorado e aperfeiçoamento na interação de ambos por meio da intensificação de capacidades democráticas (espaços de controle social e execução em conjunta), mas, no entanto, mudanças recentes parecem reforçar a participação da burocracia estatal; ii) ao longo do tempo, o Programa cresceu em termos de estrutura institucional, contudo, isto também gerou desafios em termos de adequação das regras estabelecidas às especificidades da agricultura familiar, controle de execução das mesmas e capacidades de coordenação interburocrática; e, iii) trata-se de um programa pequeno e relativamente instável em termos de orçamento.Visualiza-se que a sustentabilidade das capacidades democráticas, institucionais e financeiras do Programa é relativamente frágil. A mudança política ocorrida em 2016 no governo federal coloca novos desafios a este cenário. 


\section{Capacidades Estatais para a Construção e Execução do PNPB}

O Programa Nacional de Produção e Uso de Biodisel (PNPB) é um programa inovador que tem o objetivo de promover a inclusão produtiva de agricultores familiares na cadeia do biodiesel. Foi institucionalizado em 13 de janeiro de 2005 (lei 11.097), com o objetivo de induzir a produção em larga escala de biodiesel e, ao mesmo tempo, promover a inclusão social dos agricultores familiares do Semiárido.

$\mathrm{Na}$ formulação do PNPB destaca-se a atuação pessoal do Presidente Luís Inácio Lula da Silva como empreendedor político. Embora o biodiesel já estivesse na agenda de governo, ele aparecia como uma política de desenvolvimento tecnológico. Sua reformulação só foi possível devido às oportunidades abertas com a mudança política em $2003^{7}$. O PNPB, portanto, revela uma significativa capacidade do governo Lula para dialogar e fazer prevalecer suas decisões na agenda política (Kato, 2012).

Contudo, por se tratar de uma expressiva inovação nas políticas energéticas (Leite, 2007), a elaboração do PNPB não foi simples. Requereu a abertura de novos espaços de participação e de diálogo com a sociedade civil e com o mercado, bem como o estabelecimento de novas rotinas e interações dentro da própria burocracia estatal. A primeira dificuldade residia em colocar em negociação atores portadores de interesses muito diferenciados, como: representantes da academia, dos setores empresariais, de associações de grandes produtores agrícolas, e organizações da agricultura familiar. No que concerne às interações intraburocracias ou intragoverno, o PNPB, por ter um caráter intersetorial, necessitava da articulação entre a Presidência, o MAPA, o MDA, o Ministério da Ciência e Tecnologia (MCT), o Ministério de Minas e Energia (MME) entre outros. Desse modo, em 2003, foi formado um Grupo de Trabalho Interministerial (11 Ministérios) com o objetivo de realizar estudos sobre a viabilidade de utilização do biodiesel como fonte energética.

Para implementar o PNPB, a Comissão Executiva Interministerial do Biodiesel (CEI) tinha como desafio articular os interesses de abastecimento energético, de desenvolvimento industrial, de inclusão social e de sustentabilidade ambiental. $\mathrm{Na}$ área de energia, o MME coordenava os trabalhos, em articulação com o Centro Nacional de Pesquisa em Energia (CNPE), com a Agência Nacional de Petróleo, Gás e Biocombustíveis (ANP) e com a Petrobras. A garantia do abastecimento derivava de negociações com a agricultura empresarial e com o MAPA. A viabilidade técnica do novo combustível e a definição dos parâmetros técnicos ficaram a cargo da Casa Civil, MME e MAPA, em conjunto com a Associação Nacional dos Fabricantes de Veículos Automóveis (Anfavea) e outros segmentos representativos dos postos de gasolina e de empresas automobilísticas.

7 No período do Governo Paralelo, ainda na década de 1990, as Caravanas da Cidadania já sinalizavam para a defesa do desenho de políticas públicas em torno da agricultura familiar. A ideia da política de biodiesel estava presente também nas discussões no Instituto da Cidadania, coordenado por Luiz Pinguelli Rosa (2001-2002), que realizou amplos debates com especialistas com o objetivo de desenhar uma agenda política para a área energética. Essas experiências anteriores moldaram as políticas energéticas do Programa de Governo do PT, o qual priorizava a inclusão de setores historicamente marginalizados e já contemplava as agroenergias, ainda que de forma geral. 
Ao MDA, coordenador do Grupo de Trabalho de Inclusão Social, coube o diálogo com movimentos sociais e organizações da sociedade civil.

Para garantir a construção de um mercado de biodiesel no Brasil, o PNPB estabeleceu percentuais obrigatórios de biodiesel a serem adicionados ao diesel comercializado no país. O ritmo de aumento do percentual adicionado era decidido pelo CNPE, sabendo que, quanto maior o percentual, maior a demanda por diesel vegetal. Além disso, para promover a consolidação do mercado e garantir a oferta de biodiesel, foram instituídos leilões públicos organizados pela ANP, sendo que, de novembro de 2005, quando foi promovido o primeiro leilão, até 2015 foram realizados 45 leilões (Brasil, 2016).

Ainda que as organizações representativas da agricultura familiar reivindicassem um ritmo mais lento de crescimento da demanda de biodiesel (o setor familiar não conseguia alcançar, em pouco tempo, a produção de matéria-prima necessária), por pressão dos setores empresariais e de produtores patronais, a rampa de adição do biodiesel acabou evoluindo rapidamente (2\% - jan. 2008/ 10\% - mar. 2019).

A inclusão social foi resolvida com o Selo Combustível Social (SCS), negociado com a CONTAG, concedido aos produtores de biodiesel que promovessem a inclusão social. A Instrução Normativa (IN) de nº 02 de 30 de setembro de 2005 do MDA dispunha os critérios e procedimentos relativos ao enquadramento das empresas no Selo. As empresas detentoras do Selo Combustível Social, de acordo com a sua localização (estado), deveriam comprar uma parte de sua matéria-prima de agricultores familiares, por meio do estabelecimento de contratos e do oferecimento de assistência técnica. As compras da agricultura familiar eram comprovadas com a apresentação das DAPs. O selo garantia às empresas, por sua vez, isenção fiscal, acesso a linhas de financiamento diferenciadas do Banco Nacional de Desenvolvimento Econômico e Social e participação nos principais canais de comercialização do biodiesel, os leilões. Os beneficios gerados aos agricultores familiares eram a garantia de compra de matéria-prima; o preço pré-estabelecido e o oferecimento de assistência técnica para a mamona.

A implementação do PNPB, entretanto, só foi possível com a participação ativa da Petrobras, a maior estatal brasileira. A Petrobras mudou a sua estratégia empresarial e acabou criando, em 2008, uma subsidiária voltada especificamente para os negócios com biodiesel, a Petrobras Biocombustível (PBio). Essa foi uma das mais importantes capacidades estatais empregadas no programa (Kato, 2012). Quando foi criado, o PNPB havia estabelecido que os produtores de biodiesel seriam empresas privadas, com destaque para a Brasil Ecodiesel. Com a falência da Brasil Ecodiesel, o governo brasileiro optou por incumbir à Petrobras a tarefa de estruturação do mercado de biodiesel com participação da agricultura familiar. Dentro da estrutura corporativa da estatal, contudo, a entrada na produção de biodiesel não era um consenso (Kato, 2012). Logo a PBio se tornou a principal produtora de biodiesel no Semiárido, tendo construído três usinas para esse fim: Candeias (BA), Montes Claros (MG) e Quixadá (Ceará).

A operacionalização do SCS não foi fácil. Os custos com a produção da agricultura familiar mostraram-se elevados, pois esbarravam nas baixas escalas produtivas, na com- 
plexa estrutura de logística e em gastos crescentes com assistência técnica. O preço do biodiesel, ao mesmo tempo, era limitado pelo preço do diesel na bomba. Em 2009, por pressão do setor empresarial (em particular da PBio) o SCS sofreu modificações importantes (IN número 1 de 19 de fevereiro de 2009). Os percentuais mínimos obrigatórios de compra de matéria-prima foram alterados: a participação do NE e Semiárido foi reduzida (de 50\% para 30\%) e ampliada a participação da agricultura familiar do Norte e Centro-Oeste (10\% para 15\%). Permitiu-se também a inclusão, nos custos de aquisição de oleaginosas da agricultura familiar, dos gastos com atividades de análise dos solos, prestação de assistência técnica e doação de insumos e prestação de serviços. Essas medidas, na prática, reduziram o volume de matéria-prima a ser comprada da agricultura familiar.

Outra dificuldade enfrentada pelo programa referia-se à sua fiscalização. O MDA era o principal ator de fiscalização e monitoramento do SCS, mas esbarrava numa estrutura institucional frágil: com poucos recursos, poucos servidores e muitos consultores, o que resultava numa grande rotatividade de gestores. Todos esses fatores prejudicavam a consolidação de rotinas e de aprendizados no acompanhamento do programa. Com o andamento do programa, houve muitas denúncias de fraudes em documentos, desvios de recursos e comercialização de DAPs. Em novembro de 2014, o MDA instituiu a Câmara Técnica de Avaliação e Acompanhamento do Selo Combustível Social (Portaria número 80 de 26 de novembro de 2012), incumbida de monitorar e fiscalizar a participação da agricultura familiar no PNPB e promover o aperfeiçoamento de suas regras e normativas.

O PNPB, de um modo geral, não apresenta um custo financeiro muito elevado. Seus incentivos eram a desoneração de PIS/PASEP e COFINS em diferentes proporções, definidas de acordo com a localização da usina e a matéria-prima utilizada. Ademais, o PNPB estabelecia algumas iniciativas com o objetivo de fortalecer a inserção da agricultura familiar na cadeia produtiva do biodiesel. Esses recursos eram provenientes do MAPA, do MDA, do Ministério da Integração Nacional e do Ministério da Ciência e Tecnologia.

Avaliações com relação ao processo de implementação do PNPB ressaltam a eficiência do Programa em conformar um parque industrial produtor de biodiesel e no atendimento das metas (Flexor, 2007; Abramovay, 2008). Esses estudos, contudo, alertam para as dificuldades no atendimento dos objetivos sociais e de desenvolvimento regional. Em 2015, por exemplo, a capacidade nominal para produção de biodiesel (B100) foi de cerca de 7,4 milhões de $\mathrm{m}^{3}$ (20,4 mil $\mathrm{m}^{3}$ ao dia), enquanto a produção nacional ano foi de apenas 3,9 milhões de $\mathrm{m}^{3}$ (Brasil, 2016). Em 2015, o óleo de soja continuou sendo a principal matéria prima do biodiesel (78\%), seguida do sebo bovino com 18\%. Ao mesmo tempo, a região Centro-Oeste (44\%) permaneceu como a maior produtora de biodiesel, seguida da região Sul (38\%). Não obstante os canais de diálogo e participação desenhados e institucionalizados, os instrumentos previstos no PNPB não parecem ainda suficientes para alcançar seus objetivos anunciados de inclusão da agricultura familiar.

Atualmente, tendo em vista os resultados pouco expressivos, o arrefecimento do debate em torno dos biocombustíveis e a crise política e econômica pelas quais passam a economia brasileira e a Petrobras, a estratégia de produzir biodiesel como um vetor de in- 
clusão social e de desenvolvimento regional parece perder força. Esse quadro é acentuado com as mudanças políticas observadas no país após o impeachment da presidenta Dilma Roussef e a mudança na coalizão de governo. Na nova conjuntura, a decisão de entrada da PBio no mercado de biodiesel parece se enfraquecer, culminando com a decisão pelo fechamento da usina de Quixadá, no Ceará, em outubro de $2016^{8}$ e no crescimento das pressões pela privatização da PBio.

Assim, a experiência do PNPB sugere que: i) o Estado brasileiro teve papel central e autonomia relativa suficiente para fomentar uma nova indústria e para estabelecer regras e normativas que desafiavam interesses de atores poderosos; ii) apesar de seus problemas organizacionais, os interesses industriais foram "ouvidos" e atendidos, o que tem resultado num elevado grau de cooperação entre Estado e mercado; iii) as capacidades financeiras não parecem ser os principais limitante para a execução do Programa; iv) embora as capacidades democráticas estabelecidas, a participação de segmentos da agricultura familiar mais vulneráveis socialmente e produtores de produtos diversificados na execução e na tomada de decisões do Programa é frágil; v) não obstante os avanços, as capacidades institucionais estabelecidas são insuficientes para promover a inclusão produtiva da categoria.

\section{Considerações finais}

Desde meados dos anos 1990 e, principalmente, depois dos anos 2000, distintas capacidades estatais foram estruturadas para promover o desenvolvimento rural e a agricultura familiar no Brasil, representando um esforço importante de reversão (ou minimização) da marginalização histórica desta categoria social. Construído e aprofundado na confluência entre o protagonismo de um corpo político e burocrático com autonomia inserida, que desde os anos 1990 vinha propondo ações (ainda que marginalmente situados no espectro político) para o fortalecimento da agricultura familiar; e a atuação "cooperativa conflituosa" (Giugni; Passy, 1998) de movimentos e organizações representativos da categoria social, este conjunto de capacidades estatais manifestou-se na formulação de diversas políticas públicas (Pronaf, PAA, PNPB, políticas territoriais, seguro agrícola etc.), na conformação de estruturas políticas e institucionais (Ministério, secretarias, leis, portarias etc.), na intensificação dos espaços formais e informais de participação social, e na ampliação dos recursos públicos aplicados (ainda que inferiores aos direcionados para o agronegócio). ${ }^{9} \mathrm{~A}$ interação entre governo de centro-esquerda, burocracia estatal e SETOR. G1,Economia, Negócios. 7 out. 2010. Disponível em: < http://g1.globo.com/economia/ negocios/noticia/2016/10/petrobras-decide-fechar-usina-de-biodiesel-no-ce-e-inicia-saida-dosetor.html>. Acesso em: 20 jan. 2017.

9 Importante observar que, em algumas áreas, tais alterações e capacidades estatais não foram tão expressivas. As políticas fundiárias, de reforma agrária e criação de assentamentos rurais e de reconhecimento de terras de indígenas, quilombolas e de povos e comunidades tradicionais pouco avançaram e o Brasil segue como uma das estruturas fundiárias mais concentradas do mundo. 
sociedade civil organizada qualificaram e deram legitimidade para estruturar capacidades institucionais, democráticas e financeiras para o desenvolvimento rural que se expressaram num acelerado processo de geração de inovações nas políticas públicas. O Pronaf, o PAA e o PNPB são resultantes desse processo.

Como visto, as capacidades estatais construídas nessas três políticas públicas analisadas são distintas e dotadas de diferentes graus de sustentabilidade. Dentre as políticas analisadas, pode-se afirmar que o Pronaf é a política mais estruturada em termos de capacidades institucionais e financeiras. Não por um acaso, é também aquela que apresenta mais vigor e maior resiliência frente a mudanças no cenário político-econômico. Em termos de capacidades democráticas, ainda que as reivindicações da agricultura familiar nem sempre sejam atendidas na integralidade, o Pronaf conservou arenas de diálogo e de participação importantes. Espaços como o Condraf, os diálogos para construção dos Planos Safra da Agricultura Familiar e as diversas outras formas de permeabilidade Estado-sociedade civil são elementos essenciais para o fortalecimento das capacidades democráticas. $\mathrm{O}$ peso simbólico, histórico e político do Programa, a complexidade e estabilidade da sua arquitetura de financiamento e operacionalização, bem como a importância que lhe é atribuída pelas organizações da agricultura familiar (o Pronaf sempre é um dos principais pontos nas pautas de reivindicações) são elementos que pressionam para que suas capacidades institucionais e financeiras sejam continuamente fortalecidas. Por sua vez, ao fortalecer estas capacidades estatais, o corpo político e a burocracia angariam maior legitimidade e apoio social considerando a capilaridade nacional do Pronaf e a demanda por ele pela agricultura familiar.

Em relação às capacidades estatais relativas ao PAA, a análise aponta que o Programa apresenta frágeis capacidades financeiras; ainda que tenha incrementado suas capacidades institucionais, as mesmas complexificaram a sua execução e fragilizaram a participação de diversas organizações da agricultura familiar; e, em termos de capacidades democráticas, embora os espaços de controle social permaneçam importantes, a co-gestão do Programa entre Estado e sociedade civil foi minimizada e incrementada a participação dos entes federativos.

No caso do PNPB, como visto, as capacidades democráticas e institucionais construídas mostraram-se insuficientes para promover a inclusão produtiva da agricultura familiar (não produtora de soja) e a diversificação de oleaginosas. Com efeito, as regras e as normas estabelecidas, bem como a prevalência de diálogos e de atendimento aos interesses dos produtores de biodiesel de soja e de óleos vegetais, enfraqueceram a participação de determinados segmentos da agricultura familiar.

É importante destacar que, tanto no PAA quanto no PNPB, os complexos arranjos institucionais e políticos construídos para a sua execução e as pressões de grupos de interesses limitaram a qualificação das capacidades estatais analisadas. Os complexos arranjos institucionais construídos para a execução de ambos os programas - envolvendo diversos Ministérios e organizações do Estado, os quais apresentam limitações em termos de compartilhamentos de um conjunto de ideias, crenças e interpretações similares sobre a agricultura familiar e o desenvolvimento rural (Sabatier; Jenkins-Smith, 1999; 1993) 
-, impuseram dificuldades em termos de capacidades interburocráticas e políticas e, por conseguinte, provocaram reconfigurações nas políticas públicas e, principalmente no caso do PAA, minimização financeira e política.

Cabe salientar que, embora observado um esforço deliberado de construção e estruturação de capacidades institucionais, democráticas e financeiras para a implementação de políticas públicas para o desenvolvimento rural ao longo dos anos 2000 (ainda que com potencialidades e limitações diferenciadas, como visto nas políticas acima), isso não implicou que o Estado brasileiro tenha reduzido o apoio às elites rurais e ao agronegócio. Em um contexto de boom das commodities e de crescimento econômico acelerado, o governo conseguiu conciliar o forte apoio econômico e político ao setor empresarial agropecuário com a ampliação das políticas sociais e produtivas voltadas para a agricultura familiar. Não obstante a orientação política de centro-esquerda, o governo seguiu adotando um comportamento dual, sem alterar as estruturas de poder consolidadas.

No entanto, na medida em que a agricultura familiar foi ganhando espaço na agenda pública nos primeiros anos de 2000, reforçada pelos dados do Censo Agropecuário de 2006 (que, pela primeira vez, mostraram sua importância econômica e social no desenvolvimento do país), foram intensificando-se as disputas políticas entre os atores sociais do meio rural. Quem produz? Quanto? Onde? Que políticas são mais eficientes para os diferentes "tipos" de agricultores brasileiros? São exemplos de questões que passaram a serem discutidas e disputadas por diferentes organizações sociais, pesquisadores, grupos políticos e partidários, e gestores, produzindo distintas pressões sobre as políticas públicas.

Esse contexto aliado a mudanças na conjuntura internacional (crise econômica a partir de 2008, redução no preço das commodities etc.) e nacional (com o crescimento do discurso sobre a necessidade de ajustes fiscais e implementação de políticas macroeconômicas contracionistas e intensificação das disputas no âmbito da política nacional brasileira) deixou transparecer as fragilidades das capacidades institucionais criadas para promoção do desenvolvimento rural e da agricultura familiar. A recente extinção do Ministério do Desenvolvimento Agrário (MDA) (em maio de 2016), a dispersão de suas funções em diversas institucionalidades (a exemplo do Ministério do Desenvolvimento Agrário e Social - MDSA, e da Secretaria Especial de Agricultura Familiar e Desenvolvimento Agrário), e a mudança em boa parte da burocracia que estava à frente das políticas voltadas para a agricultura familiar, ilustram o quanto as capacidades estatais direcionadas para grupos sociais historicamente marginalizados podem ser vulneráveis às mudanças no contexto político. No caso das políticas públicas analisadas, os arrefecimentos político e financeiro do PAA e do PNPB ocorridos nos últimos anos são emblemáticos, esse último tendo sido convertido em mais um mercado voltado para indústria de óleos vegetais.

Desse modo, a pesquisa destaca a importância da experiência brasileira, caracterizada pela construção de capacidades estatais para o desenvolvimento rural que resultaram da confluência das preferências do executivo e da burocracia, com autonomia relativa, e das pressões e diálogos dos movimentos sociais da agricultura familiar com o Estado. No entanto, os desdobramentos nas políticas analisadas revelam as fragilidades dessas capaci- 
dades estatais, as quais dependem sobremaneira do ambiente político-institucional e das pressões de grupos de interesse com poder.

\section{Referências}

ABRAMOVAY, Ricardo. Uma abordagem político-cultural dos mercados de biocombustíveis no Brasil. Estudo preparatório para a Conferência da FAO (Food and Agriculture Organization) sobre mudança climática e segurança alimentar. São Paulo: 2008.

ABRAMOVAY,Ricardo;PIKETTY,Marie-Gabrielle.Política de crédito do Programa Nacional de Fortalecimento da Agricultura Familiar (PRONAF): resultados e limites da experiência brasileira nos anos 90. Cadernos de ciência E tecnologia, v. 22, n. 1, p. 53-66, jan./abr. 2005.

ACEMOGLU, Daron; ROBINSON, James A. Why nations fail: The origins of power, prosperity, and poverty. New York: Crown Business, 2013.

AQUINO, Joacir; SCHNEIDER, Sergio. 12 anos da política de crédito do PRONAF no Brasil (1996-2008): uma reflexão crítica. In: CONGRESSO LATINOAMERICANO DE SOCIOLOGIA RURAL, 8, 2010, Porto de Galinhas, Anais... Porto de Galinhas (PE):ALASRU, 2010.

BIANCHINI,Valter. 20 do pronaf: 1995:2015: avanços e desafios. Brasília: MDA, 2015.

BICHIR, R. M. Capacidades estatais para a implementação de programas de transferência de renda: os casos de Brasil, Argentina e África do Sul. Texto para discussão n. 2032.2015.

BRASIL. Agência Nacional do Petróleo, Gás natural e Biocombustíveis. Anuário Estatístico do Petróleo, do Gás Natural e dos Biocombustíveis. Rio de Janeiro: ANP, 2016. Disponível em: <http://www.anp.gov.br/wwwanp/ biocombustiveis/biodiesel>. Acesso em: 04 fev. 2017.

Conselho Nacional de Segurança Alimentar e Nutricional (CONSEA). III Conferência Nacional de Segurança Alimentar e Nutricional. Relatório final 2007. Brasília: CONSEA, 2007.

BRASIL. Conselho Monetário NacionaL. Resolução nº 2.191 de 24 de agosto de 1995 do Conselho Monetário Nacional. Crédito rural - Institui o Programa Nacional de Fortalecimento da Agricultura Familiar (PRONAF). 1995. Disponível em: <https://www3.bcb.gov.br/normativo/detalharNormativo. do?N=095168240\&method=detalharNormativo $>$. Acesso: 07 jun. 2010.

Crédito leva desenvolvimento ao meio rural. Entrevista João Guadagnin. 2015. Disponível em: < www.mda. gov.br>. Acesso em: 27 ago. 2016.

Decreto $n^{\circ}$ 8.293, de 12 de agosto de 2014. Altera o Decreto no 7.775, de 4 de julho de 2012, que dispõe sobre o Programa de Aquisição de Alimentos. 2014. Disponível em:< http://www.planalto.gov.br/ccivil_03/_ ato2011-2014/2014/Decreto/D8293.htm>. Acesso em 19 ago. 2017.

Decreto $n^{\circ}$. 4.772, de 2 de julho de 2003. Regulamenta o art. 19 da Lei no 10.696 de 2 de julho de 2003 b. Disponível em: <http://www.planalto.gov.br/ccivil_03 /decreto/2003/D4772.htm>.Acesso: 15 dez. 2011.

Decreto $n^{\circ}$. 1.946, de 28 de junho de 1996 do Presidente da República. Cria o Programa Nacional de Fortalecimento da Agricultura Familiar - PRONAF, e dá outras providências. 1996. Disponível em:<http:// www.mda.gov.br/portal/saf/arquivos/ file?fileid=2596574\&showallversionsp=f.> Acesso: 07 jun. 2010.

Instrução Normativa $n^{\circ}$ 02, de 30 de setembro de 2005. Dispõe sobre os critérios e procedimentos relativos ao enquadramento de projetos de produção de biodiesel ao selo combustível social. 2005. Disponível em:< http://www.mda.gov.br/sitemda/sites/sitemda/files/user_arquivos_627/IN\%2002\%20-\%202005\%20MDA. pdf>. Acesso em: 19 ago. 2017.

Lei $n^{\circ}$. 12.512, de 14 de outubro de 2011. Institui o Programa de Apoio à Conservação Ambiental e o Programa de Fomento às Atividades Produtivas Rurais; altera as Leis nº 10.696 de 2 de julho de 2003, 10.836 de 
9 de janeiro de 2004 e 11.326 de 24 de julho de 2006. 2011. Disponível em:< www.planalto.gov.br/ccivil_03/_ Ato2011-2014/2011/Lei/L12512.htm>. Acesso: 15 dez. 2011.

. Lei $n^{\circ} .11 .326$ de 24 de julho de 2006. Estabelece as diretrizes para a formulação da Política Nacional da Agricultura Familiar e Empreendimentos Familiares Rurais. 2006. Disponível em: < http://www.planalto.gov.br/ ccivil_03/_Ato2004-2006/2006/Lei/L11326.htm>.Acesso: 13 set. 2011.

. Lei n 10.696 de 02 de julho de 2003. Dispõe sobre a repactuação e o alongamento de dívidas oriundas de operações de crédito rural, e dá outras providências. 2003a. Disponível em: <http://www.planalto.gov.br/ ccivil/LEIS/2003/L10.696.htm> Acesso: 08 jun. 2010.

. Ministério do Desenvolvimento Agrário. Plano safra da agricultura familiar 2011/2012: alimentos saudáveis para o campo e para a cidade. Brasília: MDA, 2016.

Portaria no. 386/1997. 1997.

Brasil, Ministério do Desenvolvimento Social e Combate a Fome. PAA Data [on-line], Disponível em:< https:// aplicacoes.mds.gov.br/sagi/paa/visi_paa_geral/pg_principal.php?url=abertura> .

Acesso em 23 jan. 2017

. Ministério do Planejamento, Desenvolvimento e Gestão. Orçamento Cidadão: Projeto de Lei Orçamentária Anual - PLOA 2017. Brasília, 2016.

CASTRO, Antonio Barros de. 7 ensaios sobre a economia brasileira. 3. ed. Rio de Janeiro: Forense Universitária, 1977.

CENTENO, Miguel Ángel. El Estado en América Latina. Revista CIDOB d'afers internacionals, p. 11-31, 2009.

CINGOLANI, Luciana. The State of State Capacity: a review of concepts, evidence and measures. UNUMERIT Working Paper Series, Maastricht University, 2013-053, p.1-52. Disponível em: < http://digitalarchive. maastrichtuniversity.nl/fedora/get/guid:25cb727f-2280-41f0-a1da-ecf3ac48230f/ASSET1>. Acesso em: 31 out. 2017.

.DELGADO, GUILHERME C. Agricultura familiar e política agrícola no Brasil: situação atual e perspectivas. Reforma agrária, v. 24, n. 3, p. 5-35, set./dez. 1994.

Capital financeiro e agricultura no Brasil. São Paulo (SP): Editora da UNICAMP/Icone Editora, 1985.

Questão agrária no Brasil, 1950-2003. In: JACCOUD, Luciana.(Org.). Questão social e políticas sociais no Brasil contemporâneo. Brasília: IPEA, 2005, p. 51-90.

; CONCEIÇÃO, J.unia Cristina.P.R; OLIVEIRA, Jader José de. Avaliação do Programa de Aquisição de Alimentos da Agricultura Familiar (PAA). Texto para a discussão nº.1145, Brasília: IPEA, 2005.

DELGADO, Nelson Giordano. O papel do rural no desenvolvimento nacional: da modernização conservadora dos anos 1970 ao Governo Lula. In: DELGADO, N.G. Brasil rural em debate: coletânea de artigos. Brasília: CONDRAF/NEAD, 2010, p. 28-78.

EVANS, Peter. Autonomia e Parceria. Rio de Janeiro: Editora UFRJ, 2004.

O Estado como problema e solução. Lua Nova, n. 28-29, 1993.

Embedded autonomy: states and industrial transformation. 1995.

RAUCH, James. Bureaucracy and growth: a cross-national analysis of the effects of weberian state structures on economic growth. American Sociological Review, v. 64, n. 5, 1999.

.; RUESCHEMEYER, Dietrich;SKOCPOL,Theda (Ed.). Bringing the state back in. Cambridge: Cambridge University Press, 1985.

FEARON, James D.; LAITIN, David D. Ethnicity, insurgency, and civil war. American political science review, v. 97, n. 01, p. 75-90, 2003.

FEDERAÇÃO DOS TRABALHADORES NA AGRICULTURA FAMILIAR DA REGIÃO SUL (FETRAFSUL). Resoluções do II Congresso da FETRAF-SUL/CUT. Francisco Beltrão: FETRAF-SUL, 2007. 
FLEXOR, Georges. O Biodiesel e os desafios da inovação nas políticas públicas. Observatório de Políticas Públicas para a Agricultura, n. 9. Rio de Janeiro: OPPA, 2007.

.; KATO, Karina. Políticas de promoção dos biocombustíveis e agricultura familiar: o que sugerem as recentes experiências internacionais? In: GRISA, Catia; SCHNEIDER, Sergio. Políticas públicas de desenvolvimento rural no Brasil. Porto Alegre: Editora da UFR GS, 2015, p. 311-338.

et al. Políticas públicas, dinâmica institucional e conflito de interesses: análise do Programa Nacional de Produção e Uso de Biodiesel, 2011 (Relatório de pesquisa)

FOOD AND AGRICULTURE ORGANIZATION OF UNITED NATION, The State of Food an Agriculture 2015: Social protection and agriculture: breaking the cycle of rural poverty. FAO, 2015.

FOOD AND AGRICULTURE ORGANIZATION OF UNITED NATION, Scalling up the Brazilian School Feeding model: using south-south cooperation to chare Brazil'experience of school feeding in Latin America and the Caribbean, Rome, 2014.

FOOD AND AGRICULTURE ORGANIZATION OF UNITED NATION, Towards stronger family farms: voices in the International Year of family farming. Roma: FAO, 2014.

GIUGNI, Marco; PASSY, Florence. Contentious politics in complex societies: New social movemensts between conflict and cooperation. In: GIUGNI, Marco; McADAM, Doug; TILLY, Charles. From contention to democracy. Lanham: Rowman \& Littlefield Publishers, 1998.

GOMIDE, Alexandre de Ávila. Capacidades Estatais para Políticas Públicas em Países Emergentes: (Des)Vantagens Comparativas do Brasil. In.: ; BOSCHI, Renato Raul. Capacidades Estatais em Países Emergentes: o Brasil em perspectiva comparada. Rio de Janeiro: IPEA, 2016.

2014.

; PIRES, Roberto Rocha C. Capacidades estatais e democracia: arranjos institucionais de politicas públicas. IPEA,

GONÇALVES NETO, Wenceslau. Estado e agricultura no Brasil: política agrícola e modernização econômica brasileira, 1960-1980. São Paulo (SP): Hucitec, 1997.

GRASSI, Davi de; MEMOLI, Vincenzo. Political Determinants of State Capacity in Latin America. World Development, v. 88, p. 94-106, 2016.

GRISA, Catia. Políticas públicas para a agricultura familiar no Brasil: produção e institucionalização das ideias. Tese (Doutorado em Ciências Sociais) - Programa de Pós-Graduação de Ciências Sociais em Desenvolvimento, Agricultura e Sociedade,UFRRJ, 2012.

et al. Dinâmica institucional das políticas públicas para a agricultura familiar no Brasil: atores, ideias, interesses e instituições em jogo. 2016. (relatório de pesquisa).

et al. Governança e performance do PAA: um estudo comparativo entre Rio Grande do Sul e Rio Grande do Norte. 2015 (relatório de pesquisa).

GUANZIROLI, Carlos Enrique. PRONAF dez anos depois: resultados e perspectivas para o desenvolvimento rural. Revista de economia e sociologia rural, v. 45, n. 2, p. 301-328, 2007.

HANSON, Jonathan; SIGMAN, Rachel. Measuring state capacity: Assessing and testing the options. In: APSA annual meeting paper. 2011.

HENDRIX, Cullen S. Measuring state capacity: Theoretical and empirical implications for the study of civil conflict. Journal of Peace Research, v. 47, n. 3, p. 273-285, 2010.

KATO, Karina Y. Estatais, Políticas Públicas e Estratégias Empresariais: os caminhos da Petrobras no biodiesel. 2012. 318 f. Tese (Doutorado em Ciências Sociais) - Instituto de Ciências Humanas e Sociais., Universidade Federal Rural do Rio de Janeiro, Rio de Janeiro: 2012.

KINGDON, John. Agendas, alternatives and public policies. Boston (Mass): Little, Brown and Co, 1984.

LEITE, Antonio Dias. A energia do Brasil. Rio de Janeiro: Elsevier, 2007. 
MAHONEY,James. Path-dependent explanations of regime change: Central America in comparative perspective. Studies in comparative international development, v. 6, n. 1, 2001.

MANN, Michael. Infrastructural power revisited. Studies in Comparative International Development, v. 43, n. 3-4, p. $355,2008$.

MATTEI, Lauro. PRONAF 10 anos: mapa da produção acadêmica. Brasília: MDA, 2006.

MEDEIROS, Leonilde Servolo. Sem terra, “assentados", "agricultores familiares”: considerações sobre os conflitos sociais e as formas de organização dos trabalhadores rurais brasileiros. In: GIARRACCA, Norma. Una nueva ruralidad en América Latina? Buenos Aires: CLACSO, 2001.

MENEZES, Francisco. Participação social no Fome Zero: a experiência do CONSEA. In: SILVA, José Graziano da; DEL GROSSI, Mauro Eduardo; FRANÇA, Caio. Fome Zero: a experiência brasileira. Brasília: MDA, 2010, p. 247-264.

MIELITZ, Carlos. Dez anos de PAA e a constituição de uma estratégia nacional de segurança alimentar. In: BRASIL, MDS. PAA: 10 anos de aquisição de alimentos. Brasília: MDS, 2014, p. 58.73.

MIGDAL, Joel S. Strong societies and weak states: state-society relations and state capabilities in the Third World. Princeton: University Press, 1988.

MÜLLER, Ana Luiza. A construção das políticas públicas para a agricultura familiar no Brasil: o caso do Programa de Aquisição de Alimentos. Dissertação (Mestrado em Desenvolvimento Rural) - Programa de Pós-Graduação em Desenvolvimento Rural (PGDR/UFRGS), Porto Alegre, 2007.

PEREIRA,Ana Karine. A construção de capacidade estatal por redes transversais: o caso de Belo Monte. Tese (Doutorado em Ciência Política) - Programa de Pós-Graduação em Ciência Política (IPOL/UnB), Brasília, 2014.

PORTO, Silvio Isopo. Programa de Aquisição de Alimentos (PAA): política pública de fortalecimento da agricultura familiar e da agroecologia no Brasil. Dissertação (Mestrado em Agroecologia) - Programa Oficial de Postgrado, Baeza, Espanha, 2014.

SABATIER, Paul A.; JENKINS-SMITH, Hank C. The advocacy coalition framework: an assessment. In: SABATIER, P.A. Theories of the policy process. Westview Press, 1999, p. 117-166.

Policy change and learning: an advocacy coalition approach. Westview Press, 1993.

SABOURIN, Eric; SAMPER, Mario, MASSARDIER. Giller. As políticas de desenvolvimento rural na América Latina em perspectiva. GRISA, Catia; SCHNEIDER, Sergio. Políticas públicas de Desenvolvimento Rural no Brasil. Porto Alegre: Editora da UFR GS, 2015.

SANTOS, Fabio P. Coalizões de interesses e a configuração política da agricultura familiar no Brasil. Tese (Doutorado em Administração Pública e Governo) - Escola de Administração de Empresas de São Paulo (FGV-SP), São Paulo, 2011.

SCHNEIDER, Sergio; CAZELLA, Ademir; MATTEI, Lauro. Histórico, caracterização e dinâmica recente do Pronaf-Programa Nacional de Fortalecimento da Agricultura Familiar. In: SCHNEIDER, S.; SILVA, M.K.; MARQUES, P.E.M. (Org.). Políticas públicas e participação social no Brasil rural. Porto Alegre: Editora da UFR GS, 2004. p.21-49.

SKOCPOL, Theda. Bringing the state back: Strategies of analysis in current research. In: EVANS, P.; RUESCHEMEYER, D.; SKOCPOL, T. (Ed.). Bringing the state back in. Cambridge: Cambridge University Press, 1985.

FINEGOLD, Kenneth. State capacity and economic intervention in the early New Deal. Political Science Quarterly, v. 97, n. 2, 1982.

Wang, Erik Haixiao;YIQING, Xu. Awakening Leviathan:The Effect of Democracy on State Capacity, 1960-2009. 2017. DOI: http://dx.doi.org/10.2139/ssrn.2626849. 
WORLD BANK. World Development Report 1997: The State in a Changing World. New York: Oxford University Press, 1997. Disponível em: <https://openknowledge.worldbank.org/handle/10986/5980>. Acesso em: fev. 2015.

WORLD FOOD PROGRAMME., State of school feeding worldwide. Roma/Itália: World Food Programme, 2013.

ZIMMERMANN, Silvia Aparecida. A pauta do povo e o povo em pauta: as Conferências Nacionais de Segurança Alimentar e Nutricional, Brasil - democracia, participação e decisão política. Tese (Doutorado de Ciências Sociais em Desenvolvimento, Agricultura e Sociedade) - Programa de Pós-Graduação de Ciências Sociais em Desenvolvimento, Agricultura e Sociedade (CPDA/UFRRJ). Rio de Janeiro, 2011. 


\title{
State capacities for rural development in Brazil: analysis of public policies for family farming
}

\begin{abstract}
The paper analyzes the state capacities built for rural development and family farming in Brazil. In order to do so, the paper analyses the process of construction of three public policies (Pronaf, PNPB and PAA) and the capacity of the Stare to promote, implement and support them over the years. We understand that the state capacities created for rural development in the Brazilian State result of the processes of redemocratization and political decentralization in the 1980s that allowed the formation of institutional arrangements that expanded the interaction between government, state bureaucracy and organized civil society. This interaction, coupled with the establishment of a center-left government in the 2000s, allowed the creation of a political-institutional environment conducive to the formation of a political body and a bureaucracy that have placed family agriculture and rural development on the political agenda and have established state capacities to promote them. These state capacities, oriented toward historically marginalized segments of the population, however, are conditioned by the macro-political-institutional environment and by the unequal power relations historically established in the Brazilian countryside.
\end{abstract}

Keywords: state capacities, public policies, rural development.

\section{Capacidades estatales para el desarrollo rural en Brasil: análisis de las políticas públicas para la agricultura familiar}

\section{Resumen}

El artículo analiza las capacidades estatales instituidas para el desarrollo rural y para la agricultura familiar en Brasil. Para eso, se rescata cómo ocurrió el proceso de construcción de tres políticas públicas (Pronaf, PAA y PNPB) y busca analizar la capacidad del Estado para promorcionarlas, implementarlas y apoyarlas a lo largo de los años. Se entiende que las capacidades estatales creadas para el desarrollo rural surgieron de los procesos de redemocratización y descentralización política de la década de 1980, hecho que permitió la conformación de arreglos institucionales que ampliaron la interacción entre el gobierno, la burocracia estatal y la sociedad civil organizada. Esa interacción, asociada al establecimiento de un gobierno de centro-izquierda, a partir de los años 2000, permitió la creación de un ambiente político e institucional propicio para la conformación de un cuerpo político y una burocracia que pusieron a la agricultura familiar y el desarrollo rural en la agenda la política del país y establecieron capacidades estatales para promorcionarlos. Sin embargo, esas capacidades, dirigidas a la población históricamente marginada, son condicionadas por el entorno político e institucional y por las relaciones de poder históricamente desiguales establecidas en el Brasil rural.

Palabras clave: capacidades estatales, políticas públicas, desarrollo rural. 